thick. The brickwork of the smaller wells was $2 \mathrm{ft}$. thick;
that of the larger wells was $31 / 4 \mathrm{ft}$. thick. It was composed that of the larger wells was $31 / 4 \mathrm{ft}$. thick. It was composed
of specially made radiating bricks, set in mortar, consisting of one part of stone lime, two parts of kunkur, and six parts wells were successfully sunk through artificial islands. They were filled with concrete and connected by small arches.
The superstructure of the piers was $271 / 2 \mathrm{ft}$. long, $71 / 2 \mathrm{ft}$. The superstructure of the piers wis $271 / 2 \mathrm{ft}$. long, $71 / \mathrm{ft}$
wide, with semi-circular cutwaters. They were carried up
$21 \mathrm{ft}$. above low water. The abutments were founded on three wells, each $121 / 2 \mathrm{ft}$. in diameter, and were similar to
the piers, but flanked with longitudinalwing walls. Nearly nine wells were sunk per month. A spur of earth and
bowlders, $4,800 \mathrm{ft}$. in length, was made from the left abutment of the bridge to the high ground forming the left bank
of the river, as a protection against the river getting in rear of the river, as a protection against the river getting in rear
of the bridge abutment. Moreover, an average amount of of the bridge abutment. Moreover, an average amount of the piers. The bowlders formed a local supply of material
ready to be dropped into any holes scoured out around the piers, and gave support to the piers to resist the overturning a pair of lattice-girders, connected on the top by an upper and flat plates, braced on their under sides. This uppe a lower roadway for foot passengers and mules and ponies only. A detailed account was given of the girders and road-
ways and of the erection of the girders. The total cost of the bridge, including the protective works, had been $£ 139,502$, or £28 11s. per lineal foot.

\section{CURVED BEAMS.}

ON Trajan's column, at Rome, has stood since A. D. 114 the sculptured representation of that Emperor's bridge over the Danube, which (like the construction of the column itself) dwarfs modern efforts, with few exceptions, by its colossal nature. The bridge was $3,000 \mathrm{ft}$. in length, and had
twenty-two arches of timber, so that it is not going far aside twenty-two arches of timber, so that it is not going far aside
to allude to it in a notice of curved beams. the scarfed, the bent, the flitched, and the laminated. The first consists in making a curved beam out of straight logs, occasional during a long period, or, if sometimes forgotten, as frequently revived. Palladio used such beams, and may jan's column. About a century ago the Brothers Grubenby one of them in a bridge at Wettenghen were of formidable dimensions. The space being $230 \mathrm{ft}$., the beams were composed of seven logs in depth, with serrated tabulations without any actual bending of the wood. The heading joints in each layer were $12 \mathrm{ft}$. apart, but so arranged as to
form an interlacing bond, and the whole was strongly keyed form an interlacing bond, and the whole was strongly keyed and bolted. It was ligneous masonry. is too remarkable an instance of the difficulty encountered by ordinary literati in describing technical affairs to be neg-
lected:

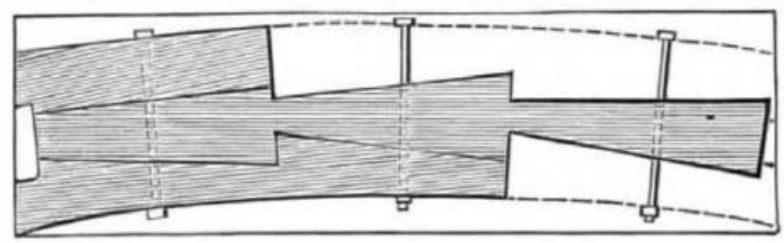

STRAIGHT LOGS CURVED IN THE TABLING.

“The abutments were $25 \mathrm{ft}$. high, and the arch between them was a catenary - that is, the same form which a rope or flexible chain assumes by its own weight when hung ove
two fixed pegs. This arch was, of course, inverted in the come manner as the iron chain bridges that have lately been constructed in this country, and, making allowances for the fair perhaps to consider it as the first chain bridge that ever was constructed in Europe.

Misled by the idea of a catena, the writer failed to reflect
that it would be as difficult to suspend an arch of that it would be as difficult to suspend an arch of timber vex upward. My illustration is not drawn from a particular example, but is intended to represent the serrated tubin rial, equal to one-third of the total quantity consumed. The large volumes of Krufft and Emy afford more express and combination than I can propose to present.
The second class began early in the present The second class began early in the present century, when
M. Wiebeking, an able German constructor, effected an imM. Wiebeking, an able German constructor, effected an im
portant improvement. He contrived to bend to the requisit portant improvement. He contrived to bend to the requisite
curvature timbers as large as 15 ins. square and $50 \mathrm{ft}$. long thus reducing the number of heading-joints and the waste
generally attendant on short pieces. For when the grain could be forced into the direction of the curve, the great labor of the serratures and the loss of material they occa-
sioned could be at once avoided. The qualities of economy and grace were thus added to the masculine character of earlierwork. With the same artist also originated the prac-
tice of increasing the depth by additional logs as the beam approved by science and experience. Mr. Herman Haupt edge of American examples, is well entitled to speak, says "the lightest and most simple system, and the one best calsolid beam of parabolic curvature, increasing in depth from the vertex to the ends."

A figure will be given in the next chapter, but nothing
could more exactly illustrate this description than the beams employed by Mr. Wiebeking in the bridge at Bamberg in are three logs in depth at the crown, and five. at the springing, keys being introduced in the longitudinal joints to prefibers are probably more vibratory than where the parts are cut to the requisite shape, according to the old rule, and this property must increase with the length in either case. There that of Grubenman over the Linnant, at Wettenghen, wa extent, and the crushing point of the material marks their cording to the of means, of which he can avail himself ac-
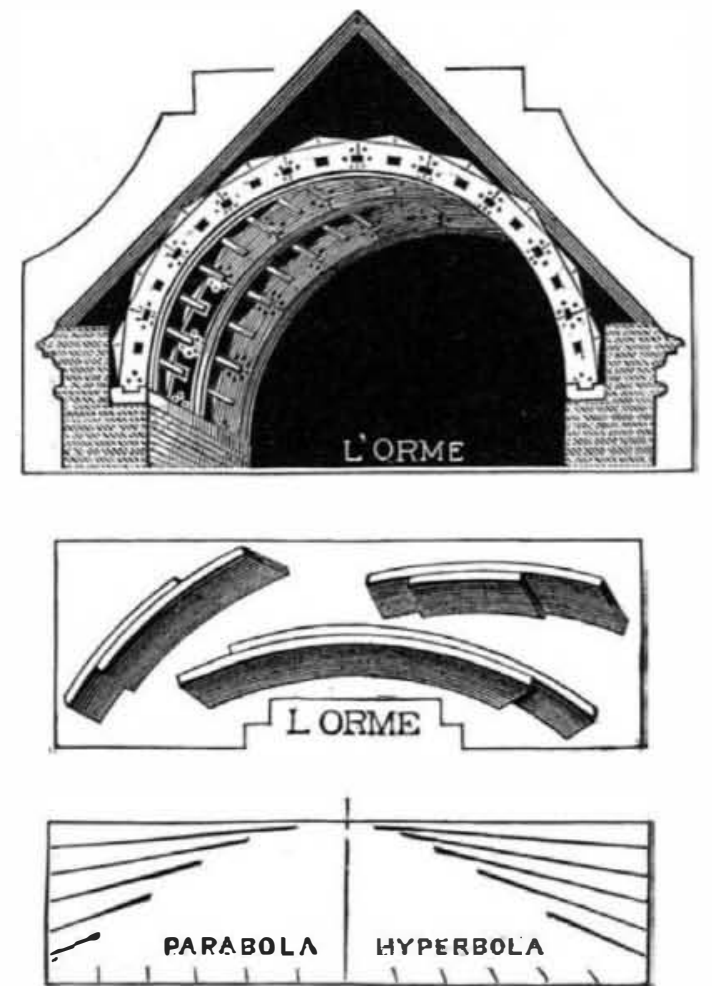
pointed or otherwise, the flat.

Whether through the survival of this suggestion, or the natural development of Wiebeking's system, modern configure and accompaniments produced a remarkable impres sion of strength, lightness, and economy. They are repre "Gwilt's Cyclopædia," and “Weale's Rudimentary Series" " Art of Building"). Unfortunately, the confined ho apor from the engines proved destructive, and the wood
as been replaced by iron substitutes.
These several methods offer to the modern carpenter a
reat choice of means, of which he can avail himself ac- only limit. But when beams of enormous dimensions, and all I would again venture to suggest the use of iron screws, exposed to the disturbance of moving loads, are supported of which the thread should cross the joint and draw the sur-
by stone abutments, the most careful provision ought to be faces forcibly together. Having at the same time an eye to

\begin{tabular}{l|l|l|} 
made, lest they crush the mortar and fracture the masonry. & the possible effect of shrinkage, it may be judicious to con- \\
Esthetics have a higher standard now than at the beginning & nect only two thicknesses with the same screw. - Building \\
of the age, and when beams constitute the leading elements & Neros.
\end{tabular} of the age, and when beams constitute the leading element of structures, it seems only fitting that their forms should
be displayed. Casing has no greatly preservative effect, and be displayed. Casing has no greatly preservative effect, and
when made to imitate stonework, degenerates into an un-
worthy deception. The carpenter his proper material, and it affords an ample range for his ability. If less monumental than stone, it is oftener pirated, the moderate yet many-centered elliptics of Sa. With regard to the third class, or flitch beams, exact in formation exists. It was the invention of a French architraveled in Ttaly, probably visited the great Vicentine, and studied his works. Returning to France, L'Orme soon ac-
quired especial eclat from this constructive novelty. "We
have no further need," said he, "of great trees for the beams

and rafters of our roofs, for they may be formed of ribs
that will seem to grow out of the walls." His mode was that will seem to grow out of the walls." His mode was
this: Stopping the inner portion of the wall at some distance elow the eaves, he placed on the bed thus formed a strong tervals he raised ribs constructed of two thicknesses of
boards of equal lengths and breadths, but commencing with a half length on one side, so as to make the abutting joint alternate. These boards being pinned and keyed together formed a rib of considerable stiffness, and commonly of
semicircular shape. Supplementary ribs were added at the eaves and apex when requisite. Three boards were some-
times joined, and the strength proportionally augmented. times joined, and the strength proportionally augmented.
It was no ephemeral contrivance, to be laid aside as soon as novelty was over, but one that has maintained a permanent only necessary to instance their use by Mr. Decimus Burton, the Regent's Park, but recently taken down. They appear hibitions, and other works of great capacity, where the effect mental character. The facility with which any form of arch

of the flitch method.
Mr. Price, in his "British Carpenter," recommendedcurved
beams on the flitch principle for bridges. but beams on the flitch principle for bridges; but that is an ap-
plication for which they are ill-suited. Neither the headplication for which they are ill-suited. Neither the head load, such as temporary roofing and skylights, over a large load, such as temporary roofing and skylights, over a large
space, these beams are eminently convenient. Mr. Price was not the first to conceive them, nor was any British car-
penter. They are due to the eminent Frenchman above penter. They are due to the eminent Frenchman above numerous exemplifications of the kind, indications of arches
made by two thicknesses of boarding, bent concentrically on Ther and name from the whole-timber and the flitch classes. This fourth sort, being compacted of thin planks or boards, Systeme d'Arcs pour les Grandes Charpentes, par A. R. Emy, by Messrs. Green, of Newcastle, in 1837. The example best known in London, however, and probably the neatest anywhere produced, was that by Mr. Lewis Cubitt, at the ter-
minus of the Great Northern Railway, King's-cross. The
station, $105 \mathrm{ft}$. in width, was spanned by semicircular ribs, station, $105 \mathrm{ft}$. in width, was spanned by semicircular ribs,
11 ins. wide and 12 ins. deep, made of nine thicknesses, and
moulded at the angles. On the baunches next the walls were open spandrels of iron, On the haunches next the walls were wood at the crown, 9 ins. wide and 12 ins deep. The dis-
tance between the principals was $20 \mathrm{ft}$., and their simple
By William Navbon, Bondsville, Mass.

A FEELING appears to be prevalent among bleach and The danger, I think, is overestimated, for if we examine carefully into the probable causes that have led to such ex-
plosions, we shall find that they are easily avoidable, and herefore, that it is incorrect to assume that high pressure keirs must be dangerous at all times and under all circum have exploded, with all the disastrous effects incident to a steam boiler explosion, and therefore I shall endeavor to
show in the present paper the causes which may lead to the
generation of forces sufficient to explode a keir, how these orces may be liberated into activity, and how the generation of such forces may be avoided and all danger of explo-
sion effectually prevented. By way of illustration, I shall sion effectually prevented. By way of illustration, I shall
take the case of a keir that burst at the print works of the Messrs. Prokeroff, at Moscow, Russia.
The keirs in question were $11 \mathrm{ft} .6$ ins. long and $6 \mathrm{ft}$. 6 fished butt joints, running in the direction of the length of the keir. These joints were single riveted with $5 / 8$ in. rivets,
the rivet heads inside the keir being countersunk. Each keir was furnished with a steam gauge, back pressure valve,
and a 3-inch safety pipe set to blow off at a pressure of 50 pounds per square inch.
Being at the works myself shortly after the explosion took place, 1 was enabled to examine the various parts of the broken keir, and also to make minute inquiries regarding all An examination of the torn edges of the plates showed
the iron to be in good condition, strong, and fibrous, and the iron to be in good condition, strong, and fibrous, and
subsequent tests proved it to possess an ultimate cohesive Now if we take one-third of this as being the permanent tenile strain the iron would bear without injury, and the that the keir could be worked at a pressure of 133 pounds per square inch with safety, and that we should have to reach a pressure of 212 pounds per square inch to burst the let 3 inches in diameter which would relieve the pressure
whenever it exceeded 50 pounds per square inch, and the orked at a pressure of over 55 pounds per square inch, hence it will be safe to infer that over-pressure of steam could not be the cause of the explosion.
If we take into consideration the fact of the joints all running in a line with the weakest portions of the keir, viz., in the direction of its greatest length, and the loss of bind-
ing force in the rivets by countersinking, and the probable hearing strength of single rivets subjected to such a direct weakest portions of the keir, and we can easily come to the conclusion that if the pressure which burst the keir had been a gradually accumulative one, it would have torn the plates asunder at the line of rivets. I found, however, that the lines of fracture ran in all directions. They did not ra-
diate from any given point, neither did they run with or even parallel to the lines of rivets, but, on the contrary, in all cases where the lines of fracture had intersected the lines of rivets
the fish plates had offered no perceptible opposing force, but
were torn across in the direct lines of fracture. It should also be borne in mind that the ease with which a 3-inch safety pipe would relieve any over-pressure renders inadmissible pe would relieve any over-pressure renders inadmissible
the theory of any gradual accumulation of pressure either fo conclude-first, that the keirs were in good condition, and
to well able to withstand any steam pressure which it was cal-
culated they should bear; second, that the keir was not exculated they should bear; second, that the keir was not ex-
ploded by steam pressure; and third, that whatever forces brought into activity instantaneously. Hence, in order to establish any theory regarding the explosion based upon any The in the construction of the keirs.

The keirs in question exploded during the process of composed of 800 gallons of water, 360 pounds of soda ash, nd 150 pounds of resin, the soda being almost a pure caronate. Any elementarywork on chemistry will tell us that stronger than itself, and that it is the weakest of all acids. stronger than itself, and that it is the weakest of all acids. the keir of any substance having a decided acid reaction would decompose the carbonate of soda and set the carbonic
acid free, and it is to this process of liberation that we may acid free, and it is to this process of liberation that we may
trace the first elements of danger. There are several ways in the keir to liberate the carbonic acid gas from its base. In the first place, the goods may not have been thoroughly washed after the previous operation of "souring." and a into the keir with the goods. Another and more probable nd consequent liberation of the carbonic acid was due to the action of the resin, as it is known that resin contains two
compounds having a strong acid reaction, and each capable
of displacing carbonic acid.

It is a recognized fact that when resin and soda are boiled ogether in the ordinary manner very little chemical change takes place; the action is almost wholly a mechanical one, quor, although it is certain that sufficient cliemical action oes take place to cause the evolution of a portion of the carbonic acid, and should the liquor be violently agitated or reases directly as the increase of the heat. There is no doubt that at a temperature such as would exist in a high pressure keir the resin would be acted upon more energeticreached at which the hydrocarbon constituents of the resin might become partially or wholly volatilized, and the acids The result would be the energetic decomposition of the carbonate of soda, and the consequent generation of a large print works managers that the use of high pressure or Bar-
ow keirs is unsafe, on account of their liability to explode. ins. diameter, made of $\frac{5}{16}$ in. iron; the joints were single could not exist, because in the safety valve we have an outdiate from any given point, neither did they run with or even ploded by steam pressure; and third, that whatever forces
were generated to cause the explosion must have been other causes than steam pressure, wear and tear, or imper- 
the limited room for expansion in keir more than two-
thirds full of cloth and liquor, working at a pressure of 45 pounds per square inch, and increase this pressure by bring. ing into active force the carbonic acid gas contained in 360 pounds of carbonate of soda, we should create a pressure
far above the bursting point of the keir, because it must be borne in mind that the increased strain would be an impulsive one, being produced instantaneously, and that all laid on gradually.

I have already shown that the safety valves and other conditions of the case preclude the possibility of a gradual accumulation of pressure either by gas or other causes, there-
fore it is necessary to show how the gas can be liberated into activity instantaneously. There are two methods by which this might be accomplished-first, by the generation of a probable; and secondly, by the sudden removal of the pres-

Carbonic acid gas is easily soluble in water even at the ordinary pressure of the atmosphere, and it becomes more soluble as the pressure is increased. Even the gas itself may be compressed into a fluid state, and if the pressure be removed the gas is immediately liberated and ex-
pands to its normal condition. (This can be illustrated by loosening the cork from a bottle of soda water.) If, therefore, we mix the gas with water at a pressure of three atmospheres, such as would exist in the keir, a large volume of it would be taken up by the liquor, and remain in a quiescent condition until a removal of the pressure, when it would be suddenly liberated and expand into forcible action. Hence, though the action of the resin may be producing a continually increasing volume of carbonic acid gas, the gas may bf taken up and remin combined with the water until a favordoubt that the would be a sudden reduction of the pressure. This reduction might be effected by either of the following causes-first, by the sudden condensation of the steam in the upper portion of the keir, and the consequent conversion of the whole of the liquor into steam and carbonic
acid gas. This, of course, could only occur through gross carelessness, such as directing a stream of cold water on the outside of the keir, which 1 have known to be done for The purpose of washing. off the and móst probable theory is that the attendarties. changing the liquor from the full keir to the empty one, waited too long before opening his liquor valve, and thus allowed the pressure in the empty keir to become much lower than the pressure in the keir upon which the steam was acting and which contained the liquor. Consequently the sudden opening of the valve and instantaneous libera-
tion of the pressure caused the violent evolution of the carsteam and liquor Of course it must be understood that both keirs were full of cloth and that in speaking that empty keir I mean the one in which there was no liquor. fully:

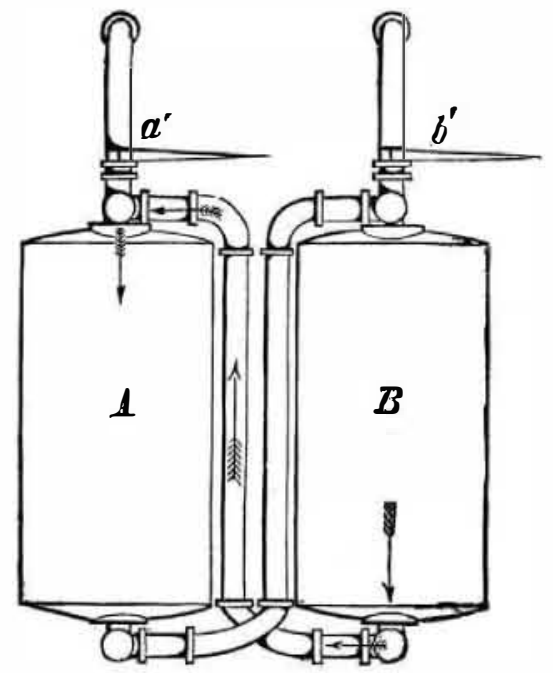

Supposing these keirs to be full of cloth, and to have been working about four hours, and the steam to be entering at
the valve, $a^{\prime}$, in the keir A, and the liquor to be all over in the keir B; the attendant, in changing the liquor back into
the keir A, would turn off the steam at $a^{\prime}$, and turn it on at $b^{\prime}$, and, after waiting a few moments to allow the pressure $A$, he would open the valve $a^{\prime}$, to allow the liquor to pass der all ordinary circumstances, if the pressure in the keir $B$ was 45 pounds, the pressure in the keir A would be the steam and the keir receivin between the keir carrying about 10 pounds; hence we see that under ordinary circumstances the actual pressure removed in changing over the
liquor is only 10 pounds; but if the attendant wait too long berore opening the valve $a^{\prime}$ to let the liquor into $A$, the pressure in A becomes rapidly diminished by condensation, length of time to reduce it to the ordinary pressure of the atmosphere, and of course as we diminish the pressure in the keir A we diminish the force opposed to the liberation of the gas when the valve $a^{\prime}$ is opened to admit the liquor.
The probability of this theory is strengthened by the fact The probability of this theory is strengthened by the fact had opened the valve $a^{\prime}$, and all the other keir explosions that have come to my knowledge have occurred under preinfer that keir explosions may be attributed to the generation of carbonic acid gas, that the carbonic acid must be brought into active force instantaneously, and that its sud-
den liberation is due to either the presence of a high degree of temperature sufficient to suddenly decompose all the chemical compounds in the keir, or to the sudden removal
of the pressure, the weight of evidence being decidedly in of the pressure, the weight of evidence being decidedly in
favor of the theory. Now at a dye works, where no resin is used in boiling there is no danger, and no explosions have ever been known to occur; but at a print works, where the use of resin is the soda in a caustic state. Caustic soda contains no car-

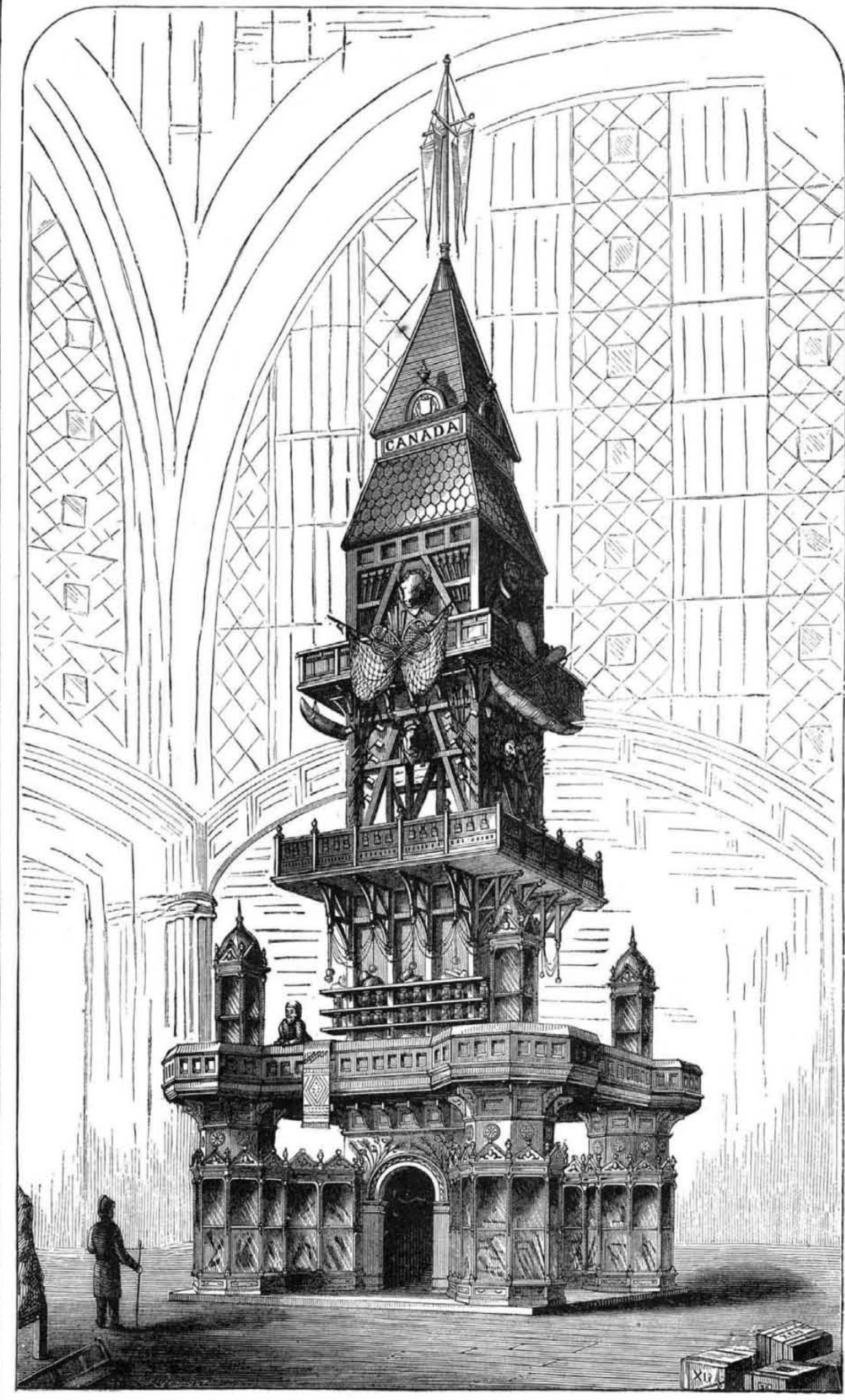

CANADIAN EXHIBIT AT THE PARIS EXHIBITION.

bonic acid, therefore none can be liberated; and with a full them; the annex for life-saving appliances, pumping ma knowledge of these facts before us, I should unhesitatingly chinery, and ports and commerce, facing the seine, while a say that, if there is no fault in the construction, there is no multitude of small buildings for French exhibits crowd the mersure keir than there is in an ord wooden keir with an open top.

THE PARIS EXHIBITION. nificent In the center of the Champ de Mars is the magnificent building of the Ville de Paris, in which France
occupies the largest space in the galleries of the Fine occupies the largest space in the galleries of the Fine
Arts. FRANCE occupies a Next in importance comes England, occupying the post of Ther countries combined will, it is true, be partly occupied by certain foreign contri- $\begin{aligned} & \text { of the Indian trophies of the President Prince of the British } \\ & \text { the }\end{aligned}$ butions, but it is essentially a French portion of the Exhibi- Commission and the exhibits of our great Eastern Empire. tion. With the exception of the pavilions of China, Japan, The Australian colonies and Canada fill the corner pavilion, all the buildings in the Trocadéro grounds are French. The which we publish an engraving. This trophy, 100 feet in principal annex is the Algerian Palace, a noble structure in which are collected the various exhibits of the colony. The ion, and of slate and other building materials. Its galleries, exts, of railway material, civil engineering, forest pro- moreover, are utilized for the display of general objects. dations, and a variety of conservatories, complete practically tions, and an annex in the rrounds, as well as the building the list of structures on this side of the Seine. The greatest constructed by Messrs. Cubitt, and generously given to the pains have been taken to develop to the utmost the garden use of the Dominion at the suggestion of the Prince of space available, for in the Champ de Mars the ground is so crow Champ de Mars, France occupies the whole of one side, the vestibule facing the Seine. Outside the main building there Britain represents fairly the part she plays in this to \begin{tabular}{l|l} 
are five French boiler-houses; thetwo grand French annexes & tion. As for annexes, we have the long agricultural shed, \\
for machinery, with the Bureaux d'Administration between & well adapted for the purpose of display, but not ornamental;
\end{tabular} 